nephew. I imagine it must be somewhat differen to $\mathrm{Mr}$. Ridsdale's specimen, judging from the variations of colour. This one has green as its predominant colour, changiving in a bright light to a brown or almost chocolate hue, and at night it is often a bright canary yellow, especially when kept, its it was on its first arrival, in a cage which was painted crean colour inside. Only once have I seen it turn white, and that wits when I was just in time to save it from being killed by a cat, and then I suppose it was the result of fear. It frequently has yellowish stripes running along its body, and sometimes round red spots. Not unfrequently one side of its body is of a different colour to the other. It drinks only sparingly, but I saw it do so this morning, putting its head right into the glass with which it is supplied.

After it had been in England about a year it surprisecl us by laying some eggs, and has done so again within the last few months. The eggs are roundish, about the size of small peas, and of a clear orange colour, somewhat resembling wrains of maize. If either Mr. Ridsdale or Mr. Bartlett would like to have one, I should be pleased to send them specimens.

The last time it changed its skin it had the misfortune to lose about half an inch of its tail, from what cause $\mathrm{I}$ am unable to say, and this has made it much less able to get about, as the loss deprived it of the little hook at the end of the tail with which it used to cling to the sticks on which it climbs. I never saw it try to help the skin off with its feet, and it has generally come off in flakes, taking a fortnight or so over it.

I think the most extraordinary thing about the reptile is the wonderful way in which the two eyes work quite independently of each other, and enable it to survey comfortably objects in quite opposite directions.

A. Alex. Blakitiox.

Glastonbury, October 21

\section{Chameleons at the Zoological Society's Gardens.}

Mr. Ridsdale must have mistaken Mr. Bartlett when he states (NATuRE, October I5) that there are no Chameleons in the Zoological Society's Gardens. We are seldom, if ever, without examples of these reptiles, and at the present moment have five specimens, three of Chameleo vulgaris from North Africa, and two of Chameleo pumilus from the Cape. At varivis times we have exhibited specimens of eight species of Chameleonidæ. I may add that Chameleons generally do not do well in captivity, and require constant attention.

3 Hanover Square, London, W., October 22.

\section{The Organisation of Technical Literature.}

The "Catalogue of Scientific Papers," compiled and published by the Royal Society of London, was intender to serve as an index to the titles and dates of scientific papers contained in the Transactions of societies, journals, and other periodical works. This Catalogue is highly valuable to all -technical inquirers, and it is a matter of deep regret that the International Conference, held under the auspices of the Royal Society of London, has decided that the International Catalogue of Scientific Literature, which is to begin with I900, is to relate to pure science only, applied science being strictly excluded. It is possibly too late to remedy the position, which is probably tue to the absence of representatives of technical sxieties at the International Conference.

It would seem desirable, further, that there should be a conference of technical societies to discuss the publication of a subject-matter index to technical and scientific periodicals. The Federated Institution of mining engineers has had for some time before it the question of the publication of such an index of subjects of interest to mining and metallurgical engineers; and probably a comprehensive index to engineering and other technical papers would prove more valuable.

This suggested conference of technical societies might also consider other questions which interest technical societics individually, but which they are unable to obtain owing to want of concerted action. Thus, such an association might approach the Government on such questions as the excessive cost of postage of Transactions, as there can be no valid reason why they should not be placed in the same position--although their Transactions are issued at varying intervals of time-by a short Act of Parliament, as an ordinary weekly newspaper.

And there are many other matters, which no doubi crop up in connection with the carrying out of the objects of individual societies, in which concerted action would produce valuable results. M. WalTon Brown, Secretary.

Neville Hall, Newcastle-upon-Tyne, October 2 I.

\section{A Mechanical Problem.}

A MAN stands in a box, whose sides, floor, and top are rigid and inelastic, the box itself being light as compared with the weight of the man, and a few inches higher than himself. The man jumps, and strikes the roof with his hands or head.

Is it possible for him to raise the box in this way (even in a small degree) perpendicularly from the ground?

"Cromerite."

[(I) The box rests on the ground. Therefore the downward push of the man on the box on springing is balanced, and no more affects the motion of the box than if his feet rested on the ground. If his muscular force were great enough, he could give infinite velocity to his body. He is now moving, the box still at rest as before. When his head strikes the top, the rate of destruction of his upward momentum is the upward force on the box, and this depends on the elasticity of his head. If his head is rigid enough he lifts the box, however heavy it may be.

(2) The "argument waged round" the question is possibly based on the idea that the box and man are in free space. In free space, nothing that the man can do will affect the motion of the centre of mass of the whole system (the box-man system) but the box itself moves, so that even in free space "the man moves the box."-J. P.]

\section{Extension of the Visible Spectrum.}

WHILE engaged on work in connection with the discharge 0 . electrification by ultra-violet light, we have come across a fact which it may be convenient to state by itself, viz. that the spectrum of an arc can be made visible over the greater part of its immense range of action on electrified metals, by receiving it upon a screen of the double fluoride of uranium and ammonium, such as is frequently used for displaying $X$-rays. The arclight must, of course, be passed through a quartz train, and a long arc is best, especially an arc containing aluminium; but under these circumstances, whereas the ordinary visible spectrum may be three-quarters of an inch broad, a breadth which may be doubled or trebled by the use of ordinary fluorescent substances, the spectrum received upon a uranium screen is five inches broad, and is full of bright lines.

Suitable screens are supplied by Ducretet of Paris, or by Chadwick of Manchester, or they can be readily made; and any one possessing either a Rowland grating, or a quarter prism and lens, can try the experiment.

It is just possible that it has not been noticed, to the full extent, before.

Liverpool, October 26. Oliver J. Lodge. Benjamin Davies.

\section{ON THE COMMUNICATION OF ELECTRICITY} FROM ELECTRIFIED STEAM TO AIR. ${ }^{1}$

$T \mathrm{HE}$ experiment described in this paper was a first slight instalment of an investigation, which we have proposed to make, of the diffusion of electricity through air, and the communication of electricity from the molecules of one gas to the molecules of another beside it or mixed with it.

By arrangements, readily imagined, we electrified dry superheated steam at atmospheric pressure by a needlepoint connected with an electric machine. The dry electrified steam was drawn off through a tube with an inlet admitting unelectrified air to mix with the steam. The mixed air and steam were drawn off through the metal worm of a still, and cooled by an abundance of cold water around the worm. The condensed water fell into a Wolff's bottle, in one neck of which the exit tube of the worm was fixed. The air, thus cooled and partially dried, was drawn out of the other neck of the Wolff's bottle through a drying tube of pumice and sulphuric acid; and thence through a short paraffin tunnel to one of our electric filters, ${ }^{2}$ insulated and connected with the

1 Abstract of communication to Section A of the British Association at Liverpool (September 2I), by Lord Kelvin, G.C.V.O., F.R.S., Magnus Maclean, and Alexander Galt.

2 "On the Diselectrification of Air," Proc. R.S., March 1875 .

NO. I 409, VOL. 54] 